\title{
EAl Endorsed Transactions

\section{Experimental Study of the Thermo-Mechanical Properties of Building Blocks Used in Hot Desert Arid Climate}

\author{
Miloud Hatia ${ }^{1}$, Abdelouahed Kriker ${ }^{1}$ and Djamel Belatrache ${ }^{2, *}$ \\ ${ }^{1}$ EVRNZA Laboratory Kasdi Merbah University of Ouargla, Algeria \\ ${ }^{2}$ Laboratory of Sustainable Development and Computer Science (L.D.D.I), University of Adrar, Algeria
}

\begin{abstract}
The desert areas in countries are characterized by their high heat, dry climate in summer and a very cold in winter. Currently, the building blocks used in the construction of slabs are found in concrete blocks, which are characterized by poor thermal performance. In the past, traditional gypsum was used to ensure that the stones used in the roof, which are shaped as domes, gave a significant thermal performance. In recent years, with the development of construction, other blocks have emerged in the market, such as scorched soil and polyester. The aim of this study is to determine the mechanical and thermal properties of the tested brick by laboratory experiments, as well as to make recommendations in line with the desert climatic conditions. The results show that the use of natural materials found in Sidi Khouield is highly efficient in reducing the internal temperature of studied houses. A maximal difference in the temperature between the inside and outside reaches $15^{\circ} \mathrm{C}$ in P3.
\end{abstract}

Keywords: Palm fibers, gypsum blocks, concrete construction, thermal insulation.

Received on 02 July 2020, accepted on 23 July 2020, published on 27 July 2020

Copyright (C) 2020 Miloud Hatia et al., licensed to EAI. This is an open access article distributed under the terms of the Creative Commons Attribution license, which permits unlimited use, distribution and reproduction in any medium so long as the original work is properly cited.

doi: 10.4108/eai.1-7-2020.165679

"Corresponding author. Email: Djamelbellatrach@gmail.com

\section{Introduction}

Residential buildings are characterized by design and operational specifications that make them affected by the changing climatic environment [1]. In the south of Algeria, especially Ouargla, due to the harsh (dry-hot) climate, residential buildings, alone, consume more than half of the used electricity [2]. Due to the design deficiencies in the thermal properties of the outer shell of buildings and the leakage of air to and from the interior atmosphere, most of the electrical energy is consumed by air conditioning systems to treat this deficiency[3]. Therefore, the choice and design of the outer shell in terms of its thermal properties, and the control of air leakage contributed effectively in reducing the consumption of electrical energy without negatively affecting the thermal comfort of building users[4-8]. Also, it is noticeable in the Algerian modern desert buildings, the total dependence on concrete and the using of the bearing elements only (columns - tributaries) in its walls and ceilings [9]. The reason for this large increase is mainly the amount of electrical energy used to operate the various air conditioners [10], that people use to expel the intense heat from inside their homes due to having poor heat resisting walls and ceilings [11]. Clay material is the most widespread material and close to the primitive man [12]. This substance attracted his attention and prompted him to use a raw material for his house and there is no doubt that the earth soil is the natural medium and the material that embraced the first human[13,14]. Although its first features have emerged in the civilizations of the East, according to all scientific data: Archaeological excavations[15-16], novels and historical observations[17], in addition to 
anthropology, it spread throughout the ancient world, and still constitute the most widespread, easiest, and least expensive architecture in the world. Therefore, it becomes the broadest human architectural heritage [18-20]. Due to the nature of the climate in the region of Ouargla[21], which is characterized by a significant change of temperature between the minimum and maximum. The high temperature in summer and cold in winter, the population has to use exploitation of local building materials, available in nature in Ouargla state by the building contractors, to suit the requirements for durability and insulation without neglecting the aesthetics in each construction $[22,23]$.

This study aims to know the mechanical and thermal properties of materials used in the roofs and walls of our desert model rooms, as well as the effect of these materials on the thermal insulation in the rooms for the experimental study that was carried out in four different construction rooms. Clay, gypsum, simple brick and "Tasammat" traditional gypsum that use these materials in Sidi Khouiled city, Ouargla.

\section{Completion of Gypsum Building Blocks:}

\subsection{Manufacturing method}

Samples are prepared from pure gypsum as follows: By putting the amount of water required for the mix in a mixing bowl, then add the amount of gypsum and mix well until obtaining a homogeneous paste, taking into account the time of mixing so that no more than (01) one minute. Then, prepare the mold and fat with a quantity of oil to get a proper brick fill the mold and settle it with a ruler. At the end leave the mold in the air to dry the brick (normal drying). $32 \mathrm{~L}$ of water used for $40 \mathrm{~kg}$ of gypsum $(\mathrm{P} / \mathrm{E}=0.8)$ [24]. The mold is shown below in the figure 1 .

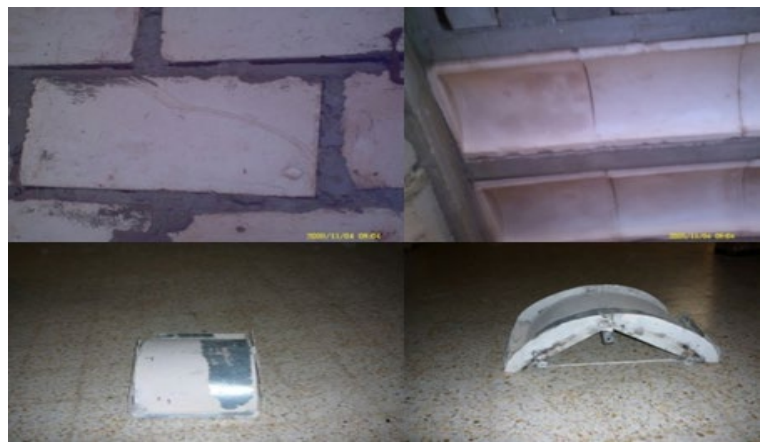

Figure 1. The use of gypsum blocks for the ceiling and walls in the city of Ouargla.

\subsection{Experimental study of thermal and mechanical properties of blocks:}

\section{- Description of thermal conductivity measuring device:}

Thermal conductivity meter (CT-meter) is a device that allows the measurement of thermal conductivity as well as the specific heat of some materials such as: building blocks, rocks, foam concrete, etc. It is a non-destructive monitoring device for the tested samples. It is also useful for knowing the tested materials in terms of homogeneity and unit properties

\section{- Four-point flexure test- NFP18-407:}

The experiment is carried out on the building blocks that are used in the ceilings and roofs from the following materials: Concrete, scorched soil, polyester, gypsum by using a machine (type CONTROLS) as shown in the Figure 2 below, where the device is equipped with movable support (horizontal movement) below. The upper part has got a vertical motion where it is driven by hydraulic pressure (the experiment used is inspired by NFP18-407). The machine is provided with a solid piece of metal placed on top of the tested sample. The load is applied to the sample continuously at a speed of $0.5 \mathrm{kN} / \min$ until the sample collapses.

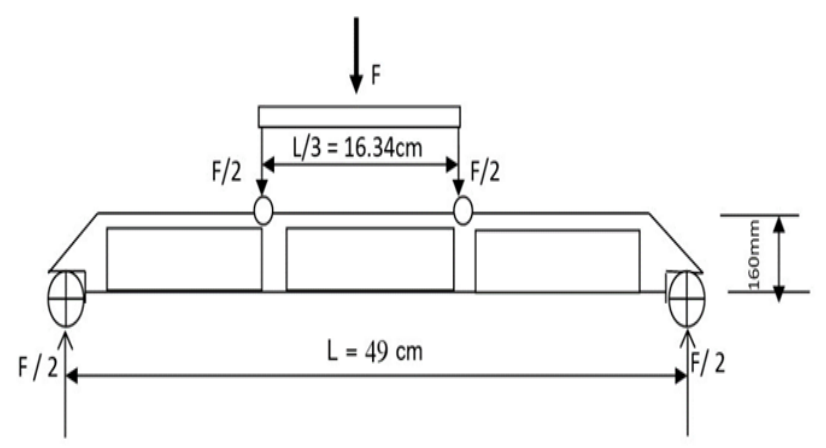

Figure 2. Four-point flexure test

The value of the force leading to collapse is given directly from the machine. The tensile stress calculation relationship is given using the following relationship[25]:

$\delta_{\mathrm{t}}=3 . F / 2 \alpha^{2}$

where:

F: Force applied to the sample.

$\alpha$ : The height of the tested sample

- Tensile bursa with three-point bending: EN 196-1:

This experiment is performed on the pure gypsum completed block using a machine of type (CONTROLS). 
This process is performed by the bending machine mentioned above and generates the value of the force leading to collapse directly from the machine[26]. This experiment is inspired by EN 196-1. Figure 3 is a schematic shape of the bending machine. The relationship of tensile stress calculation is given using the following relationship: [27]

$\delta_{\mathrm{t}}=(5 / 8) \times\left(\mathrm{P} / \mathrm{f}^{2}\right)$

Where:

P: Force applied to the sample. F: Height of the tested sample.
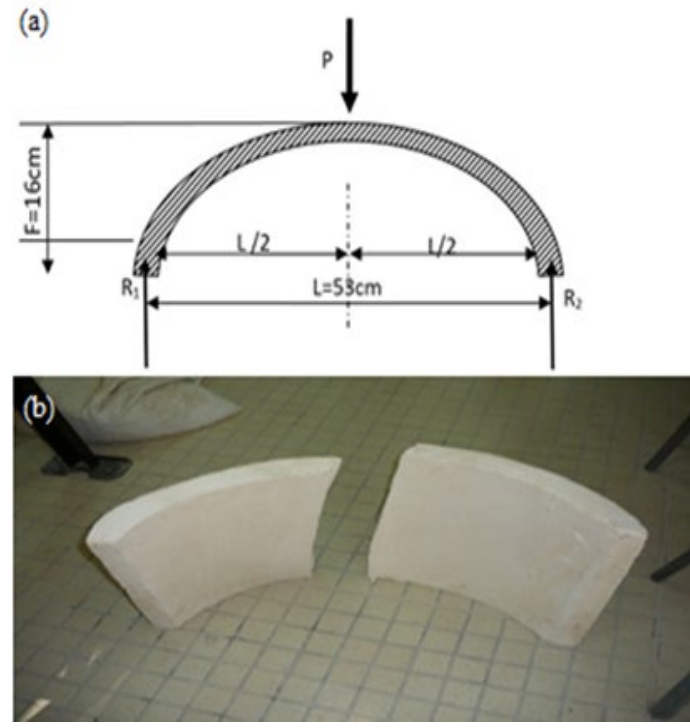

Figure 3. (a): Tensile bursa with three-point bending.

(b) The sample after the collapse.

- Simple Compression Experience - Inspired by NFP18406:

This experiment is carried out using the CONTROLS compression machine on the completed samples of concrete, scorched soil and polyester used in the roof. The machine is equipped with two fixed bottom plates and the upper moving hydraulic pressure system where the sample is placed in their centres as shown in table 1 . The two plates are square where $a=200 \mathrm{~mm}$. The load is applied to the sample in a continuous manner at a speed of $5 \mathrm{kN} / \mathrm{min}$ until the sample is depleted. The reading of the value of the force leading to collapse collapses directly from the machine.

The relationship used in compression stress calculation: $\delta \mathrm{p}=(\mathrm{F} / \mathrm{S})(3)$

Where: P: value of the force leading to the collapse of the sample. S: Plate area supplied to the machine. Where $\mathrm{S}=$ $40000 \mathrm{~mm}^{2}$

\section{- Experience the measurement of ultrasonic waves speed:}

It is a very important experiment that allows us to know several properties of solids without cracking them, and it depends mainly on measuring the speed of propagation of ultrasonic waves within the material to be studied. In this method, pulses are produced by ultrasonic waves that travel through the tested part and their transmission time is determined. The speed of the pulses through a solid object is determined by the density of the material tested and its elastic properties. The device consists of a small measuring box that records the time and extends from two long wires in the head of both cylindrical piece with a flat surface (transmitter and receiver). This method is used in the field of concrete to conclude the following:

$>$ The value of concrete resistance to pressure.

$>$ Detection of cracks and gaps in the concrete or sample tested.

$>$ Monitoring the development of concrete resistance to pressure.

\section{- Test Method:}

This test requires high efficiency. The device is adjusted with the calibration plate supplied with the device before starting the test on the sample. The distance of the pulses is measured accurately (i.e. the length of the walk). The transmitter and receiver are placed on the sample. The contact between the surface of the transmitter and the receiver and the surface of the sample is be fully used. When placing the transmitter and receiver on the sample, this situation continues until proven reading and if the results oscillate between two readings taken the average. The pulse speed (V) Calculated as follows.

$\mathrm{V}=\mathrm{L} / \mathrm{T}$

\section{Where:}

\section{$\mathrm{L}$ : Length of the measured track \\ $\mathrm{T}$ : Wave transmission time}

Table 1; illustrates the four devices used in thermal conductivity, ultrasonic waves speed and Compression.

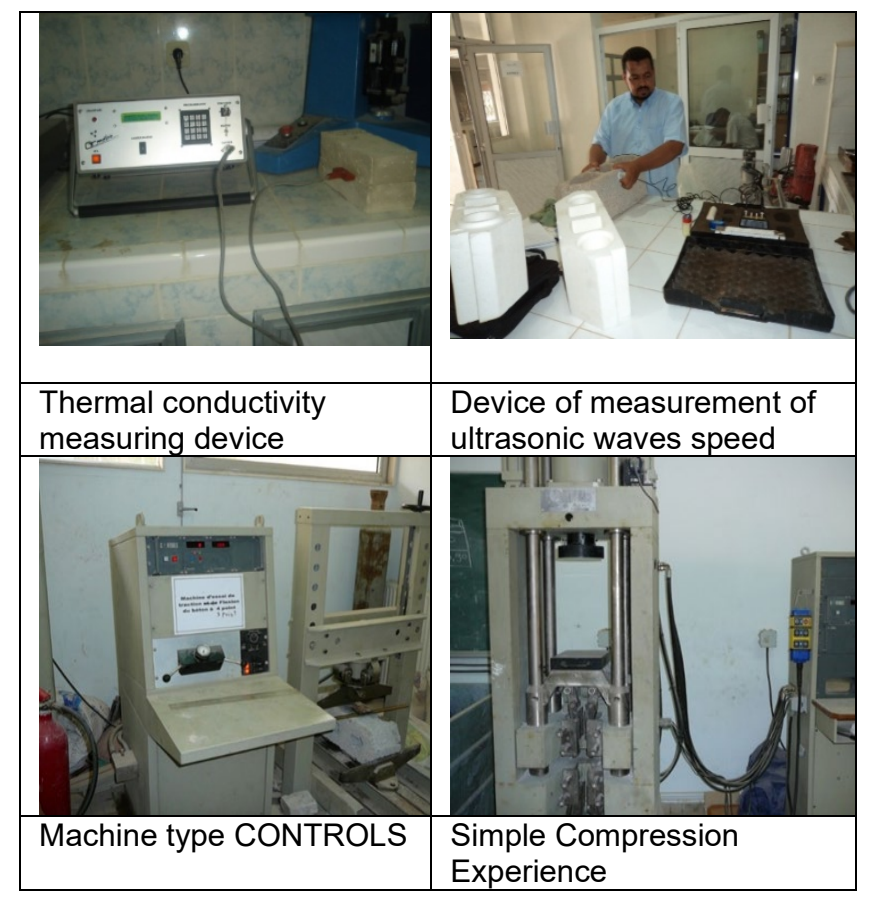

This experiment is based on the construction of 4 experimental models built by different samples of building 
blocks in the completion of walls as well as in the completion of the roof. On these objects, the degree of effect of temperature is measured by studying the thermal difference between the inside and outside by measuring the temperature of the bicycle inside and outside the model, in addition to the development of a device to measure the humidity of the center of the models.

\subsection{Specifications of models}

The models shown in the table below:

Table 2. The models and their properties.

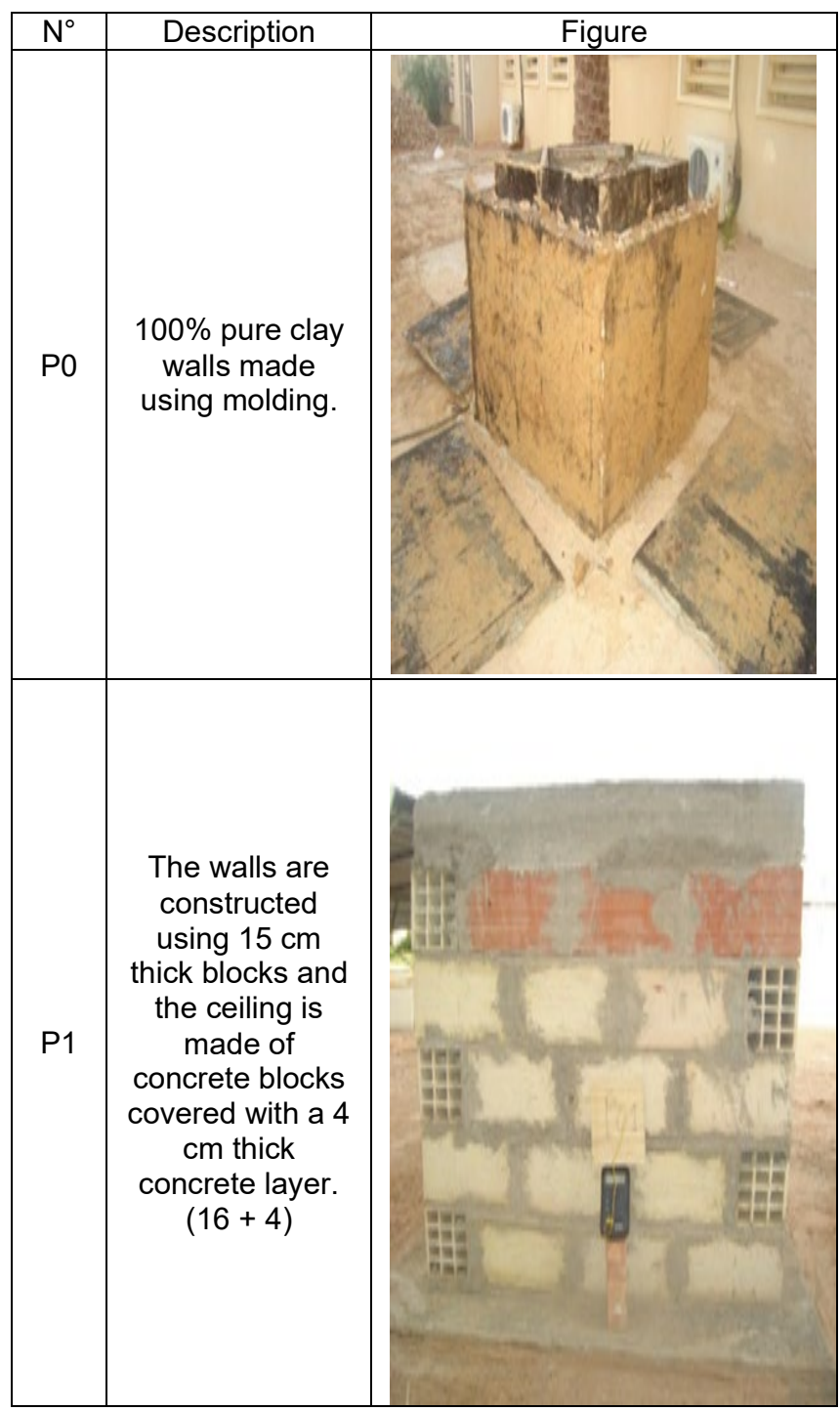

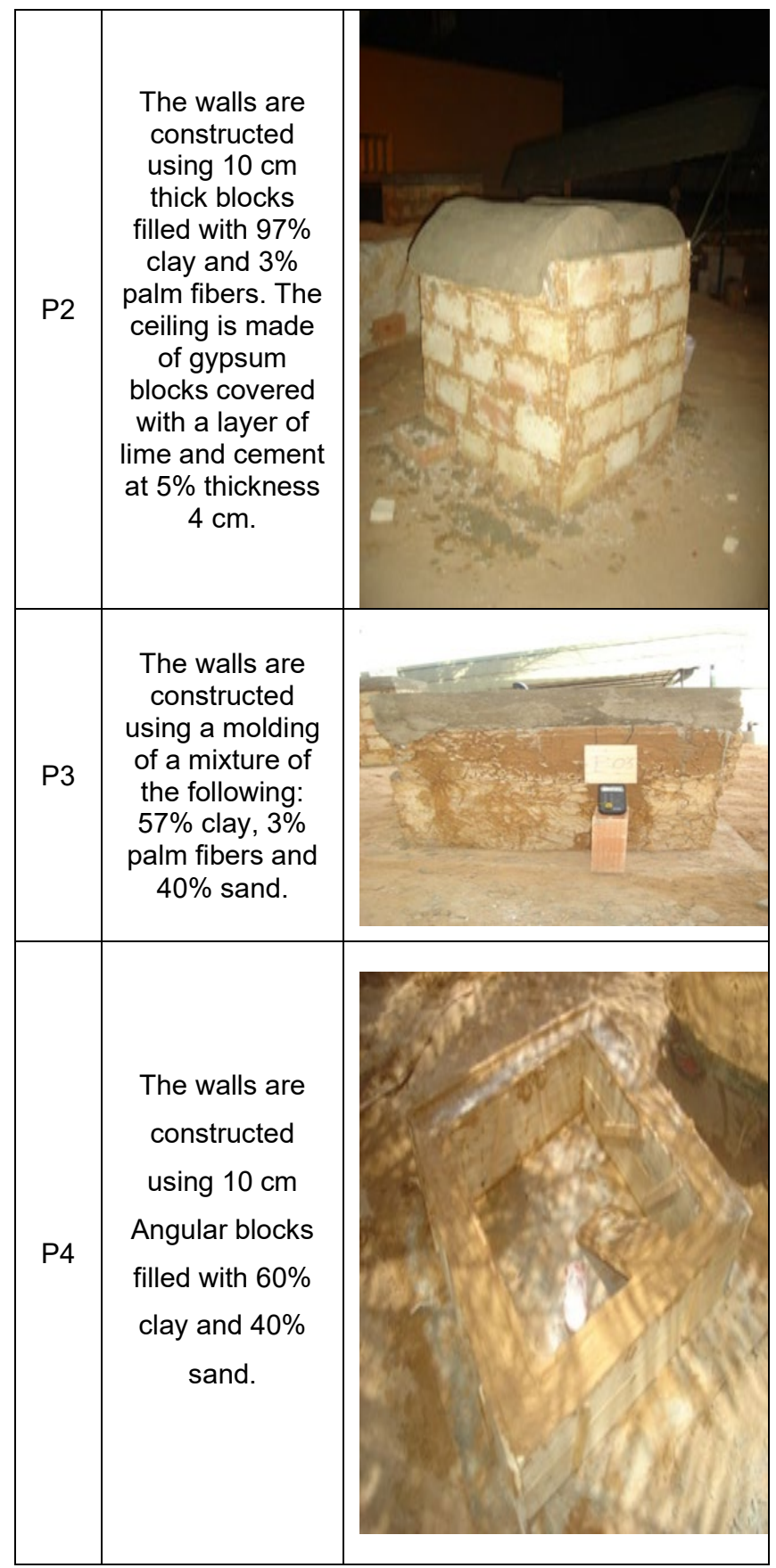

\section{Results and discussion:}

\subsection{Concrete building blocks}

\subsubsection{Thermal experiments:}

Results of thermal experiments for concrete blocks are shown in Table 03. 
Table 3. The results of thermal experiments for concrete blocks

\begin{tabular}{|c|c|c|c|c|c|}
\hline $\begin{array}{c}\text { Sample } \\
\text { number }\end{array}$ & 1 & 2 & 3 & 4 & 5 \\
\hline Weight (g) & 16340,5 & 16741,5 & 16876 & $\begin{array}{c}17097, \\
5\end{array}$ & 17100 \\
\hline $\begin{array}{c}\mathrm{T}_{0} \\
\left({ }^{\circ} \mathrm{C}\right)\end{array}$ & 20,77 & 22,91 & 21,74 & 20,84 & 22,44 \\
\hline $\begin{array}{c}\Delta \mathrm{T} \\
\left({ }^{\circ} \mathrm{C}\right)\end{array}$ & 0,32 & 0,19 & 0,21 & 0,28 & 0,24 \\
\hline$\lambda(\mathrm{W} / \mathrm{m} \cdot \mathrm{k})$ & 1,058 & 1,083 & 1,092 & 1,095 & 1,105 \\
\hline $\begin{array}{c}\mathrm{C}_{\mathrm{sp}}(\mathrm{KJ} \\
\left./ \mathrm{m}^{3} \mathrm{k}\right)\end{array}$ & 9176 & 9874 & 10770 & 10985 & 11633 \\
\hline $\begin{array}{c}\mathrm{R}\left(\mathrm{m}^{2} \cdot \mathrm{k} /\right. \\
\mathrm{W})\end{array}$ & 0,151 & 0,147 & 0,146 & 0,145 & 0,144 \\
\hline
\end{tabular}

$\lambda=1.0866 \pm 0.0916$

$\mathrm{C}_{\mathrm{sp}}=10487.40 \pm 733.466$

$\mathrm{R}=0.147 \pm 0.0018$

Table 3, shows the thermal experiments for concrete blocks for five different simples, which increase in size and change the difference in temperature according to the size of the piece, the thermal insulation strength and thermal resistance. Where: $\lambda$ : Thermal conductivity, $\mathrm{C}_{\mathrm{sp}}$ : Specific heat, $\mathrm{R}$ : Thermal resistance, $\mathrm{T}_{0}$ : Measurement temperature. $\Delta \mathrm{T}$ : Temperature deference.

The figure 4.a, shows that there is a direct correlation between the mass of the sample and the thermal conductivity, where the greater the mass the greater the thermal conductivity (Note that the tested samples have the same size). Also in figure 4.b, there is a direct correlation between the specific heat and thermal conductivity where the greater the specific heat increased thermal conductivity.

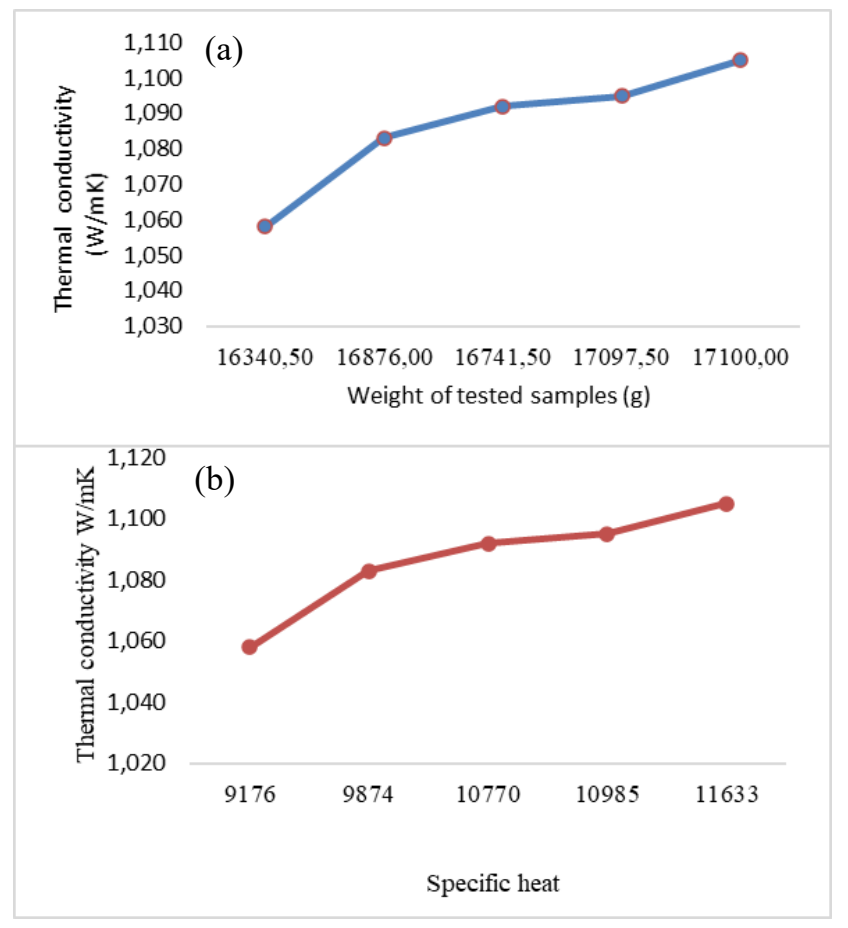

Figure 4. The variation of thermal conductivity :(a) Weight; (b) Specific heat.

\subsubsection{Determination of the Ultrasonic Waves Speed:}

The results of the calculation of ultrasonic waves velocity for concrete are illustrated in Figure 5.

Figure 5.a, confirms that the speed of ultrasonic waves is directly proportional to the thermal conductivity and this has to do with the structure of the tested building blocks where the more the tested block containing spaces, the greater the penetration time of ultrasonic waves and thus the speed of penetration is reduced. The velocity of ultrasound penetration is significant in the more weighted sample. This indicates that the samples with small velocity contain spaces, which increase the penetration time, while samples with the velocity are small and the penetration time is small too.

The figure 5.b, shows that the velocity of ultrasonic waves is inversely proportional to the thermal resistance of the tested elements i.e. the reverse thermal conductivity.

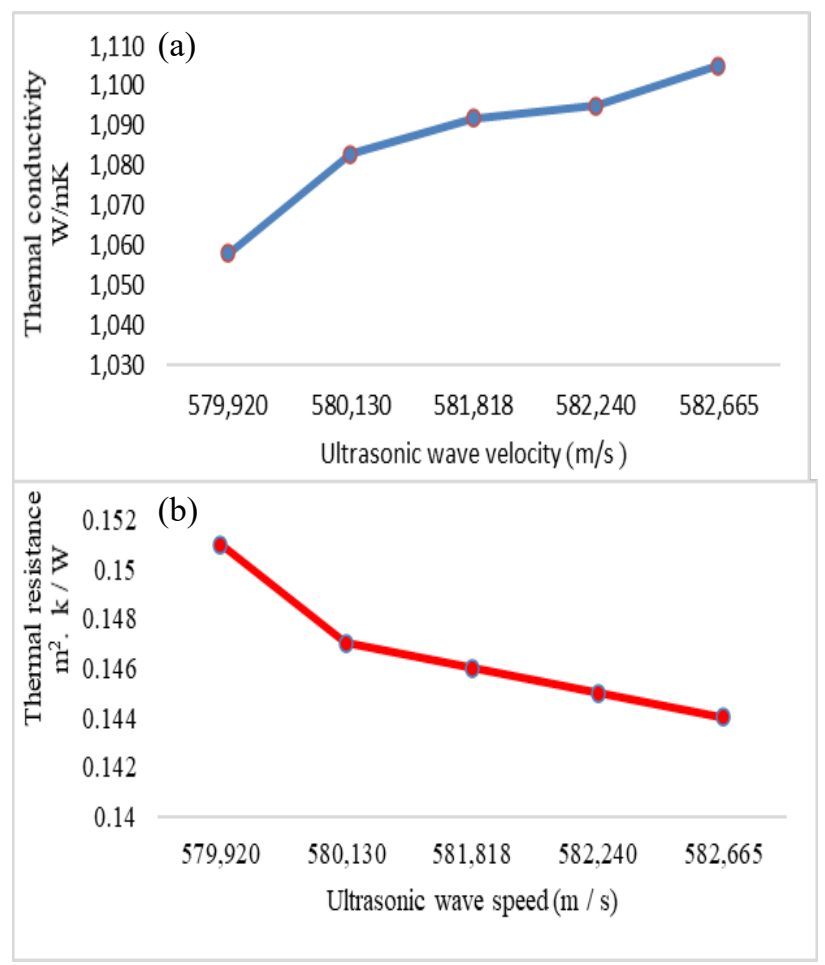

Figure 5. The variation :(a) Thermal conductivity;(b) Thermal resistance: In terms of ultrasonic velocity

\subsubsection{Mechanical experiments:}

Table 4. presents the results of the tensile experiment of concrete blocks

\begin{tabular}{|l|l|l|l|l|l|}
\hline $\mathbf{N}^{\circ}$ Sample & $\mathbf{1}$ & $\mathbf{2}$ & $\mathbf{3}$ & $\mathbf{4}$ & $\mathbf{5}$ \\
\hline $\mathbf{F}($ KN) & 2,57 & 1,80 & 2,18 & 2,48 & 2,54 \\
\hline$\sigma_{t}$ (MPa) & 0,150 & 0,105 & 0,127 & 0,145 & 0,148 \\
\hline
\end{tabular}


$\mathrm{F}=2.3144 \pm 0.242$

$\delta \mathrm{t}=0.135 \pm 0.015$

The results of compression experiment for concrete blocks is shown in the Table 5 .

Table.5. Results of compression experiment for concrete blocks

\begin{tabular}{|l|l|l|l|l|l|}
\hline $\mathbf{N}^{\circ}$ Sample & $\mathbf{1}$ & $\mathbf{2}$ & $\mathbf{3}$ & $\mathbf{4}$ & $\mathbf{5}$ \\
\hline $\mathbf{F}$ ( KN) & 36,40 & 36,80 & 37,40 & 37,50 & 36,80 \\
\hline${ }_{\mathrm{C}}$ (MPa) & 0,910 & 0,920 & 0,935 & 0,937 & 0,920 \\
\hline
\end{tabular}

$\mathrm{F}=36.98 \pm 0.340$

$\delta \mathrm{c}=0.924 \pm 0.0092$

From table 4 and 5, it's noted that both the tensile stress and the compressive stress rise as the value of force applied.

\subsection{Building blocks of burnt soil}

\subsubsection{Thermal experiments:}

- Results of thermal experiments on building blocks of scorched soil:

Table.6 Results of thermal experiments for the bricks on the scorched soil.

\begin{tabular}{|c|c|c|c|c|c|}
\hline $\mathbf{N}^{\circ}$ & $\mathbf{1}$ & $\mathbf{2}$ & $\mathbf{3}$ & $\mathbf{4}$ & $\mathbf{5}$ \\
\hline Weight (g) & 1080 & 1086 & 1088 & 1089 & 1110 \\
& 7.2 & 1.2 & 1.75 & 8.8 & 3.8 \\
\hline $\mathbf{T}_{\mathbf{0}}\left({ }^{\circ} \mathbf{C}\right)$ & 19,51 & 19.58 & 20,50 & 20,41 & 18.17 \\
\hline $\boldsymbol{\mathbf { T }}\left({ }^{\circ} \mathbf{C}\right)$ & 0,64 & 0,62 & 0,57 & 0,59 & 0.67 \\
\hline $\boldsymbol{\lambda}(\mathbf{W} / \mathbf{m} . \mathbf{k})$ & 0.565 & 0.568 & 0.578 & 0.581 & 0.585 \\
\hline $\mathbf{C}_{\mathbf{s p}} \mathbf{( K J}$ & 4900. & 5069. & 5769. & 5783. & 5 \\
$\left.\mathbf{I m}^{\mathbf{3}} . \mathbf{k}\right)$ & 2 & 30 & 2 & 2 & \\
\hline $\mathbf{R}\left(\mathbf{m}^{\mathbf{2}} \mathbf{. k} / \mathbf{W}\right)$ & 0,283 & 0,281 & 0,276 & 0,275 & 0,273 \\
\hline
\end{tabular}

$\lambda=0.575 \pm 0.0082$

$\mathrm{C}_{\mathrm{sp}}=5630.40 \pm 292.049$

$\mathrm{R}=0.278 \pm 0.003$

Table 6, shows the thermal experiments of bricks on scorched soil, for five different simples, which increase in size and change the difference in temperature according to the size of the piece, the thermal insulation strength and thermal resistance.

\subsection{The polyester building blocks:}

It's noted from Figure 6.a that there is a direct correlation between the thermal conductivity and the mass of the tested building blocks. Figure 6.b, shows the extent of thermal conductivity in terms of specific heat. Also, there is a direct correlation between the specific heat and the thermal conductivity where the higher the specific temperature, the greater the thermal conductivity, knowing that the tested samples have got the same size.
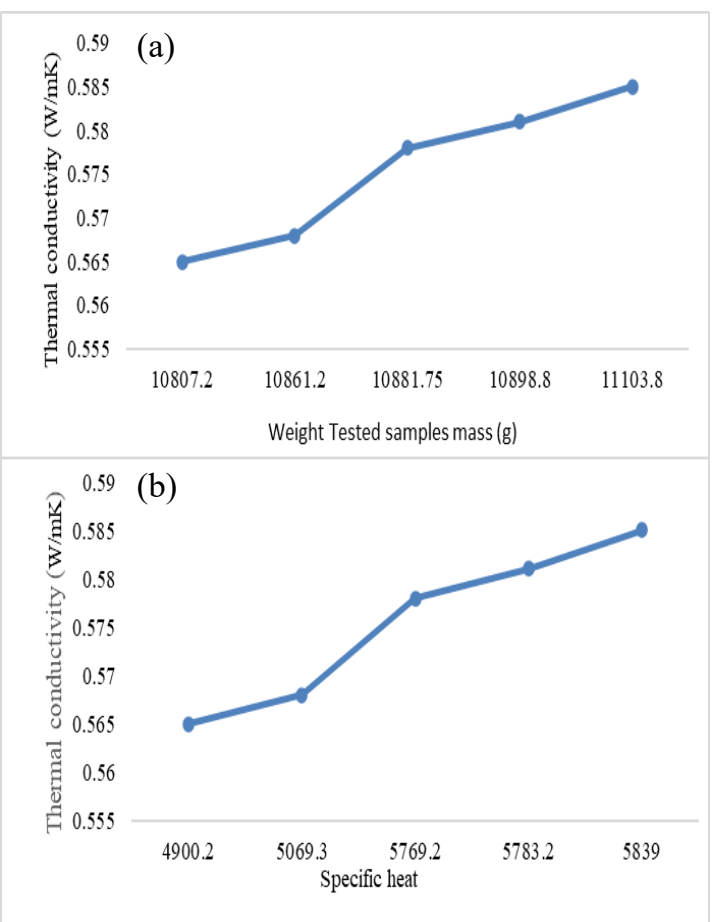

Figure 6. The variation of thermal conductivity:

(a) Weight; (b) Specific heat

\subsubsection{Thermal experiments}

Thermal experiments are not conducted because the available device does not contain a thermal probe that allows measuring the thermal conductivity of the polyester material. Therefore, the value of the thermal conductivity of this material was obtained through the references used in the completion of this paper [25]:

$\lambda=0.045(\mathrm{~W} / \mathrm{m} . \mathrm{k})$

$\mathrm{R}=4.571\left(\mathrm{~m}^{2} . \mathrm{k} / \mathrm{W}\right)$

\subsubsection{Calculate ultrasound speed}

Table 7. Results of the ultrasound velocity calculation for polyester building blocks. 


\begin{tabular}{|c|c|c|c|c|c|}
\hline Sample & $\mathbf{1}$ & $\mathbf{2}$ & $\mathbf{3}$ & $\mathbf{4}$ & $\mathbf{5}$ \\
\hline $\begin{array}{c}\mathbf{T} \\
\mathbf{( \mu \mathbf { s } )}\end{array}$ & 355,70 & 356,30 & 356,20 & 357,40 & 358,30 \\
\hline $\mathbf{V ~ ( \mathbf { m } / \mathbf { s } )}$ & 449,817 & 449,059 & 449,185 & 447,677 & 446,553 \\
\hline
\end{tabular}

$\mathrm{V}=448.458 \pm 1.307$, where $\mathrm{T}$ : time of ultrasound, $\mathrm{V}$ : velocity.

Table 7, presents the variation of the ultrasound velocity calculation for polyester building blocks with the ultrasound variation. It's noted that, the velocity decreases with increasing ultrasound.

\subsubsection{Mechanical testing}

- The results of the tensile experiment of polyester building blocks:

Table 8. Results of the tensile experiment of polyester building blocks

\begin{tabular}{|c|c|c|c|}
\hline $\mathbf{N}^{\circ}$ sample & 1 & 2 & 3 \\
\hline $\mathbf{F}(\mathbf{K N})$ & 1,47 & 1,31 & 1,80 \\
\hline$\sigma_{\mathrm{t}}(\mathbf{M P a})$ & 0,086 & 0,076 & 0,105 \\
\hline
\end{tabular}

$\delta \mathrm{t}=0.089 \pm 0.01$

\section{- Compression experience:}

Table 9. Results of compression experiment for concrete blocks

\begin{tabular}{|c|c|c|c|}
\hline $\mathbf{N}^{\circ}$ sample & 1 & 2 & 3 \\
\hline $\mathbf{F}(\mathbf{K N})$ & 4,50 & 4,60 & 4,50 \\
\hline${ }^{6} \mathrm{C}(\mathbf{M P a}) \mathbf{N} / \mathbf{m m}^{\mathbf{2}}$ & 0,112 & 0,115 & 0,112 \\
\hline
\end{tabular}

$\delta \mathrm{c}=0.113 \pm 0.001$

$\mathrm{F}=4.553 \pm 0.3459$

Tables 8 and 9 show contrast tension and compression stress with different forces applied. It is always noticeable that the increase in strength increases the two parameters.

\subsection{The polyester building blocks:}

\subsubsection{Thermal experiments:}

\section{Results of thermal experiments on gypsum blocks:}

Table 10, shows the thermal experiments of the gypsum brick, for five different structures, which increase in size and change the difference in temperature according to the size of the piece, the thermal insulation strength and thermal resistance.

Table 10. The thermal experiments for the gypsum brick.

\begin{tabular}{|c|c|c|c|c|c|}
\hline $\mathbf{N}^{\circ}$ & 1 & 2 & 3 & 4 & 5 \\
\hline $\begin{array}{c}\text { Weigh } \\
\mathbf{t}(\mathbf{g})\end{array}$ & $\begin{array}{c}16759 . \\
50\end{array}$ & $\begin{array}{c}16809 . \\
00\end{array}$ & $\begin{array}{c}16896 . \\
00\end{array}$ & $\begin{array}{c}17008 . \\
50\end{array}$ & $\begin{array}{c}17089 . \\
40\end{array}$ \\
\hline $\left.\mathbf{T}_{\mathbf{0}}{ }^{\circ} \mathbf{C}\right)$ & 30,71 & 31.06 & 31.04 & 29,35 & 29,23 \\
\hline $\begin{array}{c}\Delta \mathbf{T} \\
\left({ }^{\circ} \mathbf{C}\right)\end{array}$ & 0,43 & 0.46 & 0,49 & 0,58 & 0,56 \\
\hline $\begin{array}{c}\boldsymbol{\lambda}(\mathbf{W} / \mathbf{m} . \\
\mathbf{k})\end{array}$ & 0,812 & 0,846 & 0,849 & 0,867 & 0,875 \\
\hline $\begin{array}{c}\mathbf{C}_{\mathbf{s p}} \\
\mathbf{( K J} \\
\left.\mathbf{I m}^{\mathbf{3}} \cdot \mathbf{k}\right)\end{array}$ & $\begin{array}{c}8953,7 \\
0\end{array}$ & $\begin{array}{c}10495, \\
80\end{array}$ & $\begin{array}{c}10545, \\
00\end{array}$ & $\begin{array}{c}10690, \\
70\end{array}$ & $\begin{array}{c}10870, \\
00\end{array}$ \\
\hline $\begin{array}{c}\mathbf{R}\left(\mathbf{m}^{2} .\right. \\
\mathbf{k} / \mathbf{W})\end{array}$ & 0,061 & 0,059 & 0,059 & 0,057 & 0,057 \\
\hline
\end{tabular}

$\lambda=0.849 \pm 0.0019$

$\mathrm{C}_{\mathrm{sp}}=9706.06 \pm 690.408$

$\mathrm{R}=0.058 \pm 0.0012$

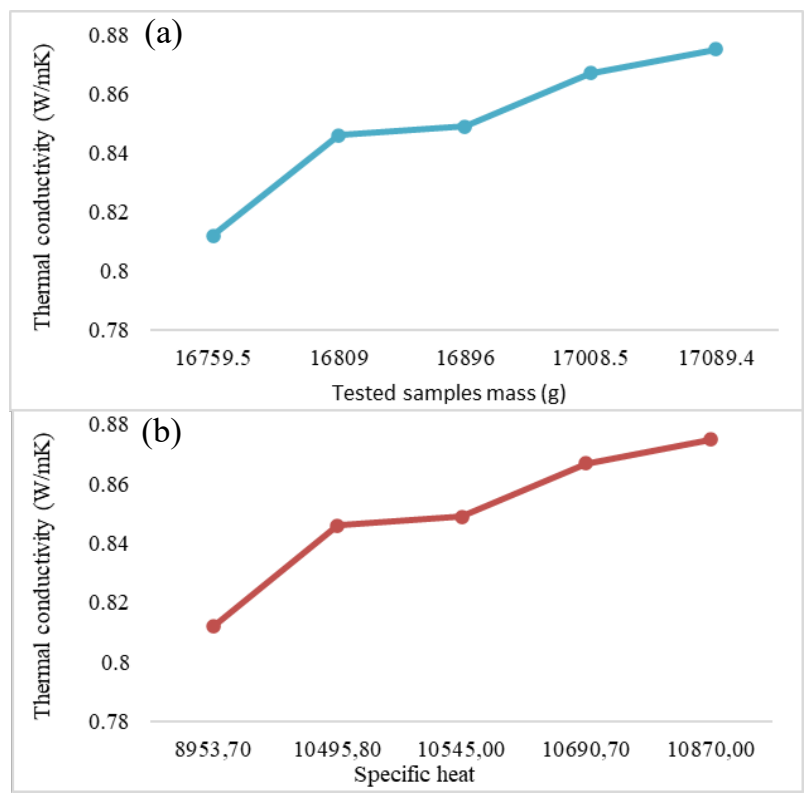

Figure 7. The variation of thermal conductivity :(a) Weight; (b) Specific heat

From the figure 7.a, it is noted that there is a direct correlation between the thermal conductivity and the mass of the tested building blocks (the volume mass is proportional to the thermal conductivity) of the tested samples the same size. Also, in Figure 7.b, there is a direct correlation between the specific heat and the thermal conductivity where the higher the specific temperature, the greater the thermal conductivity. 


\subsubsection{Calculate ultrasound speed:}

Table 11. Results of the ultrasound velocity measurements of polyester blocks

\begin{tabular}{|c|c|c|c|c|c|}
\hline sample & $\mathbf{1}$ & $\mathbf{2}$ & $\mathbf{3}$ & $\mathbf{4}$ & $\mathbf{5}$ \\
\hline $\begin{array}{c}\mathbf{T} \\
\boldsymbol{\mu s})\end{array}$ & 21.70 & 21.60 & 21.50 & 21.40 & 21.30 \\
\hline $\mathbf{V}(\mathbf{m} / \mathbf{s})$ & 2304.147 & 2314.814 & 2325.581 & 2336.448 & 2347.417 \\
\hline
\end{tabular}

$\mathrm{V}=2324.681 \pm 14.094$

Through the Table 11, it is noted that the velocity of the ultrasound is proportional to the thermal conductivity and this has to do with the structure of the tested building blocks, whereby whenever the tested block contains voids, the time of penetration of the ultrasound waves increase and thus, the speed of penetration decreases.

\subsection{Results of the experiments carried out on the rooms:}

The experiments are conducted on models in August 2011 in the yard of the Department of Irrigation and Civil Engineering at the University of Ouargla. The results obtained are shown in Figure 8.

\section{- Model room (P1):}

Figure 8 , shows the change in the internal and external temperature and humidity in terms of the hours of the day.

It is noted that the internal temperature in the morning is around $31^{\circ} \mathrm{C}$. This is due to the fact that concrete is a substance stored for heat (the phenomenon of a thermal furnace) After that, it begins to rise until it reaches its maximum at about 17:00 in the evening. Then, it decreases slightly and settles. Also, it is noticed that there is proportionality directly between the internal and external thermal rise, except at sunset. The external heat begins to decrease due to the lack of heat radiation, as opposed to the internal heat, which remains almost stable, and this is due to the storage of building elements to heat and lost at night, and this is due to the immediate thermal (heat transfer always from the hot medium to the cold). Also its noticed is that this widespread model used in our buildings does not meet the minimum conditions of thermal comfort. Also, the use of air conditioners almost never stops and this is reflected in the consumption of electrical energy.

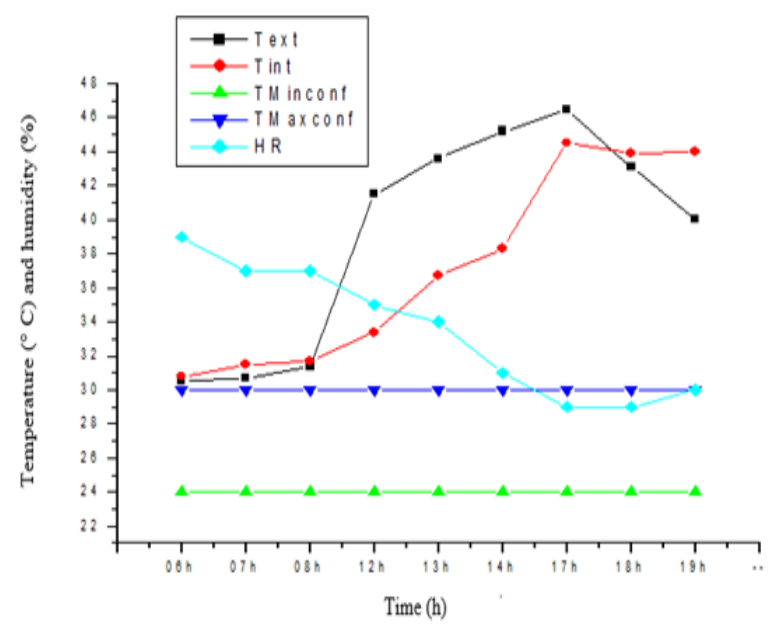

Figure 8. Change of the internal and external temperatures and humidity during the day

\section{- The difference between internal and external temperatures (P1):}

Figure 9, shows the difference between the internal and external temperatures during the day. It's noticed that during the first hours, the temperature inside is greater than the outside because the slab made of concrete is during the day absorbing and storing heat and with no solar radiation it starts to lose heat (the heat is transferred from the hot medium to the cold medium). But during the middle of the day until 17:00, the external temperature remains greater than the interior (solar radiation). After 17:00 in the evening, the opposite becomes the reason mentioned previously and it is a storehouse of building elements heat (slab and walls). In this model, the difference in temperature reaches about 8.1 and this is due to the walls made of wages (containing voids).

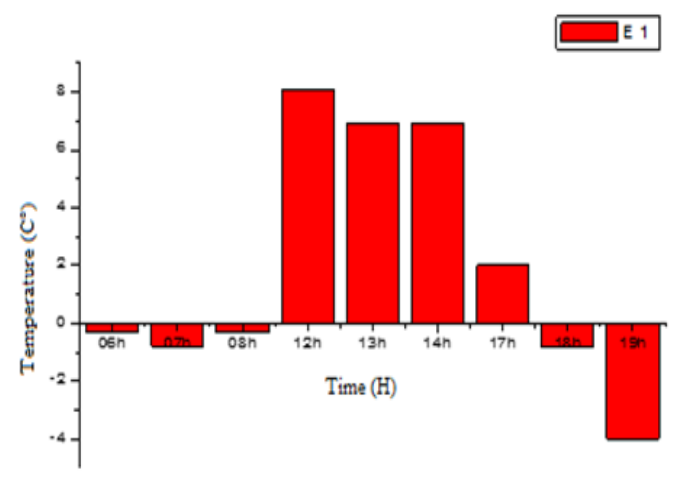

Figure 9. Variation of the internal and external temperature in the room $\mathrm{P} 1$. 


\section{- $\quad$ Model room (P2):}

Figure 10, shows the change of internal and external temperatures and humidity in terms of day hours. It is noted that in this model, the materials used to accomplish the building blocks, whether used in the walls or the ceiling, play an important role. The results obtained show that, knowing that the building blocks, including the walls, its thermal transfer walls are the smallest of the other building blocks tested, as well as the ceiling completed from the half-cylindrical gypsum building blocks. In this case, the roof is always shaded, except at noon, and the arched ceilings increase the speed of the air passing over its curved surfaces, which increases the effectiveness of the cooling winds in reducing the temperature of these ceilings. What is noticed in this model is that around midday the model is inside the thermal comfort area.

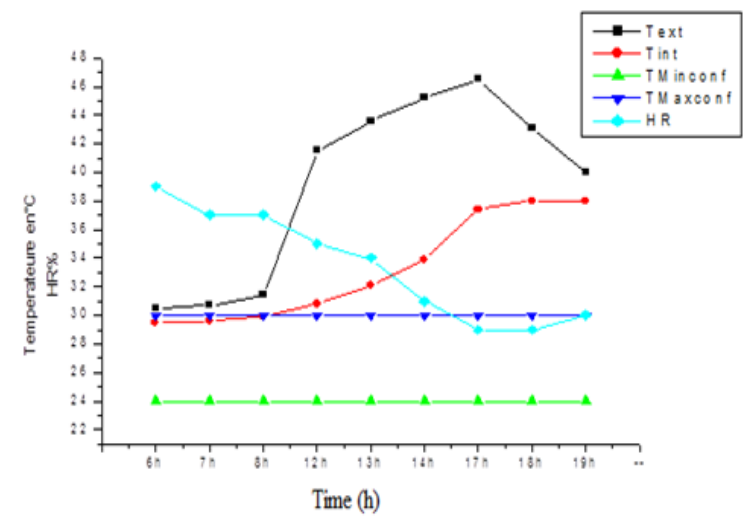

Figure 10. Changes of the internal and external temperatures and humidity during the day hours

- The difference in internal and external temperatures (P2):

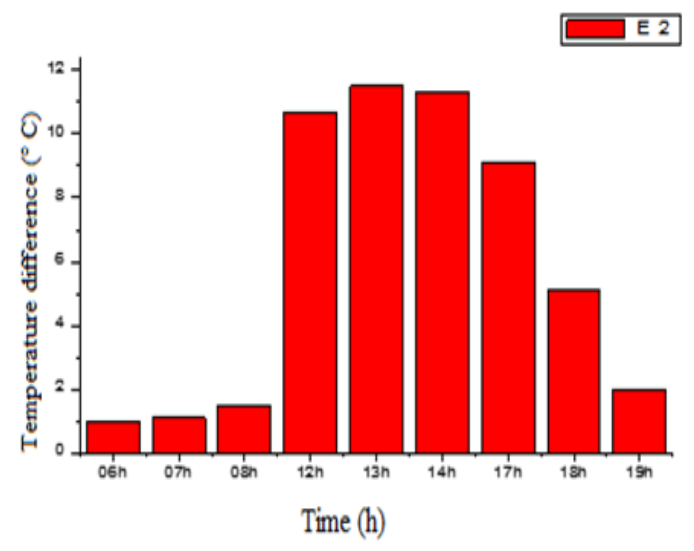

Figure 11. Variation of the internal and external temperatures during the day.
From P2, it is noted that the difference between the internal and external temperature is clear due to the good thermal resistance of the walls brick and the semicylindrical gypsum blocks made from the ceiling. Also, it refers to the loss of gypsum to the heat absorbed quickly, as well as the wall blocks. In this model, it can use air conditioners after midday and this is due to the fact that the inertia resulting from the building blocks filled (4

Clay + fibers) delayed the thermal transfer from the outside to the inside. What is also noticed is that the difference in the temperature reached $11.50^{\circ} \mathrm{C}$ at noon, which is important and good. Figure 11, shows the difference in the internal and external temperatures in terms of the hours of the day.

- $\quad$ Model room (P3):

Figure 12, shows the change in the internal and external temperature and humidity in terms of the hours of the day

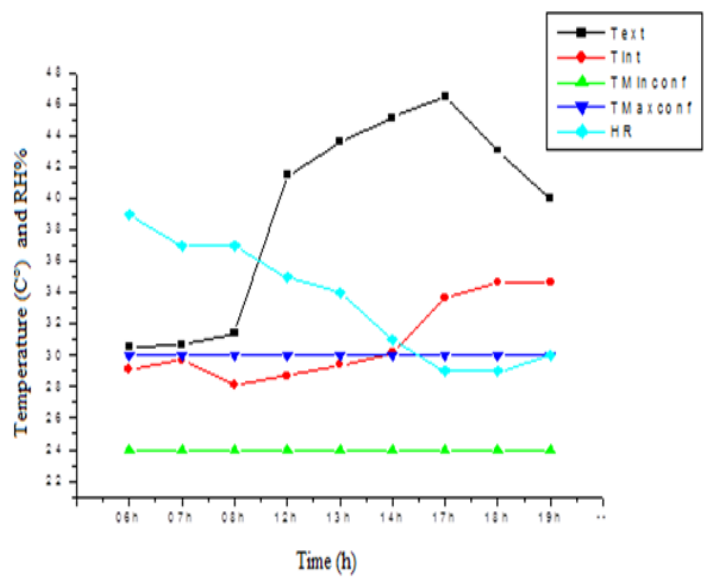

Figure 12. Internal, external temperatures and humidity variation in terms of the hours of the day

It is noted in this model that the internal temperature until the second after the meridian is still approximately $30^{\circ} \mathrm{C}$ and this means that it is necessary to use the air conditioners after 14:00 and at 17:00 hours the internal temperature stabilizes or approximately $35^{\circ} \mathrm{C}$. This model can be seen as a good one, and that the temperature does not exceed $30^{\circ} \mathrm{C}$ - the thermal comfort range extended from 6:00 until 14:00.

- The difference in internal and external temperatures (P3):

Figure 13, shows the difference in the internal and external temperatures in terms of the hours of the day. There is a clear difference between the internal and external temperature, and this, if anything indicates the role played by the polyester roof that has a great heat resistance, as well as the walls made of blocks that have 
good heat resistance. The difference is up to $15^{\circ} \mathrm{C}$ between inside and outside at 14:00.

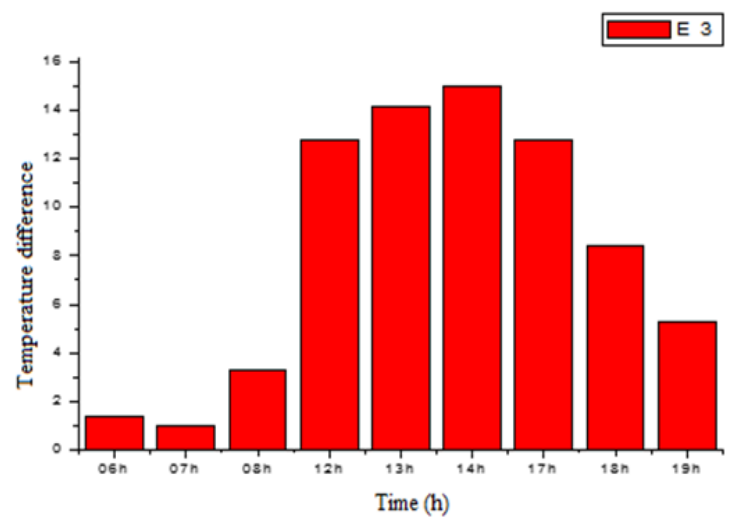

Figure 13. Variations of the internal and external temperatures in terms of the hours of the day.

\section{- Model room (P4):}

Shows the change in the internal and external temperatures and humidity in terms of the hours of the day

From figure 14, it is noticed that there is a direct correlation between the rise in the internal and external temperature, where the higher the external temperature is, the higher the internal one gets. What is also observed in this model is that the internal temperature since 8:00 in the morning exceeds $30^{\circ} \mathrm{C}$ which means that the air conditioner must be used and this has an effect on the consumption of electrical energy. The field of thermal comfort is achieved from 06:00 until 20:00.

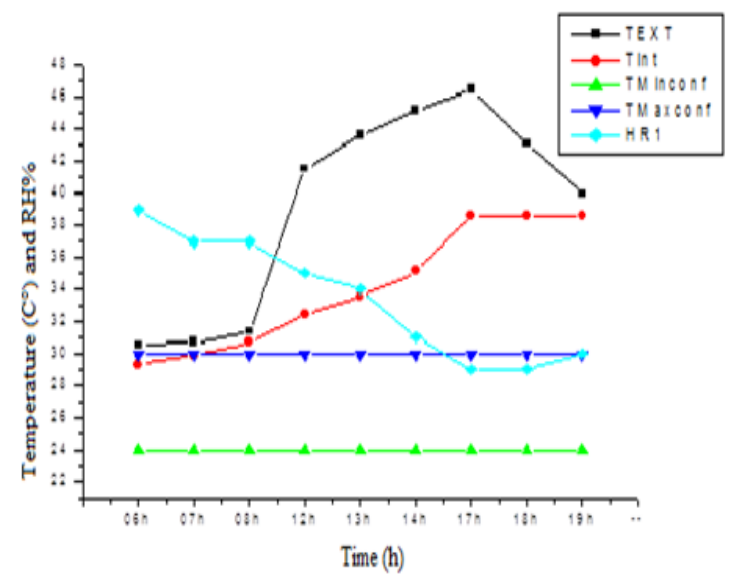

Figure 14. Changes of the internal, external temperatures and humidity during the day.

\section{- The difference between internal and external temperatures (P4):}

Figure 15, presents the variation of the internal and external temperatures during the day. The roof and the walls do not play a role because the internal temperature changes with the change in the air temperature, and this indicates an easy penetration of heat from the outside to the inside, but in return there is a difference in temperature reaches up to $10^{\circ} \mathrm{C}$. Figure 16 , shows the change in the internal, external temperature and humidity in terms of the hours of the day.

The third model (P3) is the one that provides thermal comfort to humans and also helps not consuming electrical energy and the cost of the size of air conditioners (energy consumption). This is the opposite of the models P1 and P4. The second model (P2): The walls completed from the building blocks of its thermoplastic are smaller than among the other building blocks tested, as well as the ceiling completed from the half cylindrical gypsum building blocks. In this case, the ceiling is always shaded except at noon and the arched ceilings increase the speed of air passing over its curved surfaces, which increases. The effectiveness of cooling winds to reduce the temperature of these ceilings. The comparing between the second and third models, the third is better because polyester building blocks are very expensive and are a non-local material. As for gypsum blocks, they can be done locally and cheaply, so the use of this model in our desert environment. The measured external humidity is between $30 \%$ and $39 \%$ throughout the measurement periods of humidity, these percentages are within the thermal comfort field in relation to humidity $30 \%$ $70 \%$ ), but their effect is positive if the temperature values are present in the thermal comfort area $\left(24^{\circ} \mathrm{C}-30^{\circ} \mathrm{C}\right)$. The person's feeling of heat increases as the relative humidity of the air increases.

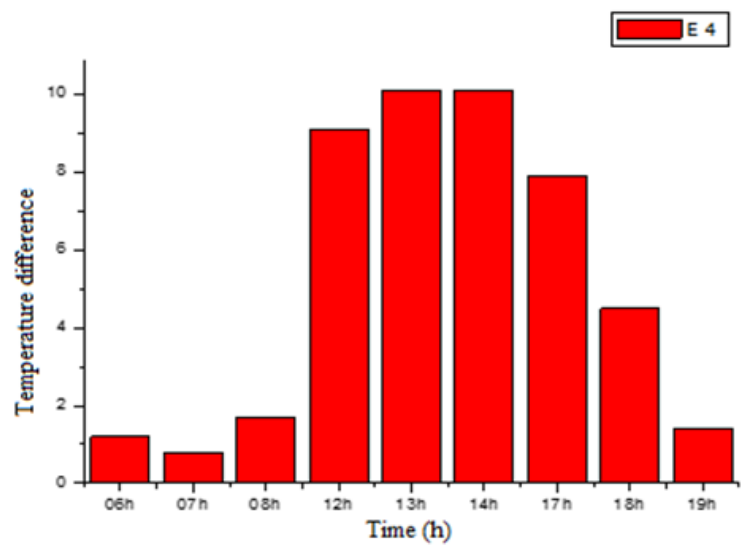

Figure 15. Variation of the internal and external temperatures during the day. 


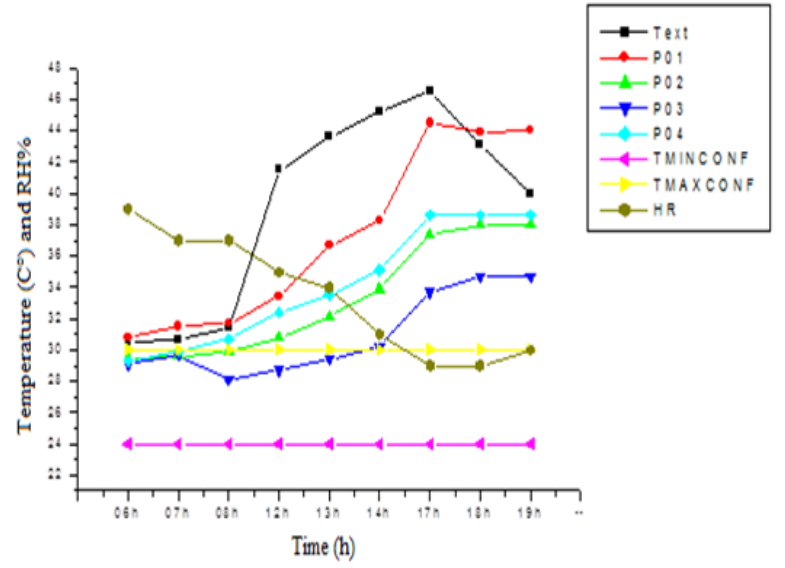

Figure 16. Internal, external temperature and humidity variation during the day.

Also, figure 17 shows the change in the difference between the internal and external temperatures in terms of the day hours for all the studied models. From figure 17, it is noted in the model P3 that there is a clear difference between the internal and external temperature, and this, if anything indicates the extent of the role played by the polyester roof that has a great heat resistance, as well as the walls made of blocks that have a large heat resistance.

In the P4 model there is a direct correlation between the rise of the internal and external temperature, where the higher the external temperature is, the higher the internal one gets. Furthermore, it is observed in this model the internal temperature since eight changes of the internal in the morning exceeds $30^{\circ} \mathrm{C}$ which means that the air conditioner must be used and this has an effect on the consumption of electrical energy.

While it is observed in the P2 model that the difference between the internal and external temperature is clear due to the good thermal resistance of the walls and semicylindrical gypsum blocks made of the roof. Also, due to the loss of gypsum by the absorption of heat quickly, as well as the wall blocks, as well as the shape of the building blocks used in the ceiling, give an improvement in thermal performance.

In addition, in model P1, during the first hours the temperature inside is greater than the outside because the slab and the walls during the day absorb and store the heat, and with no solar radiation, they start to lose heat (the heat is transferred from the hot medium to the cold medium). But, during the middle of the day until 17:00, the external temperature remains greater than the interior (solar radiation). After 17:00 in the evening, the opposite becomes the reason mentioned previously, which is the storage of building elements, heat (slab and walls).

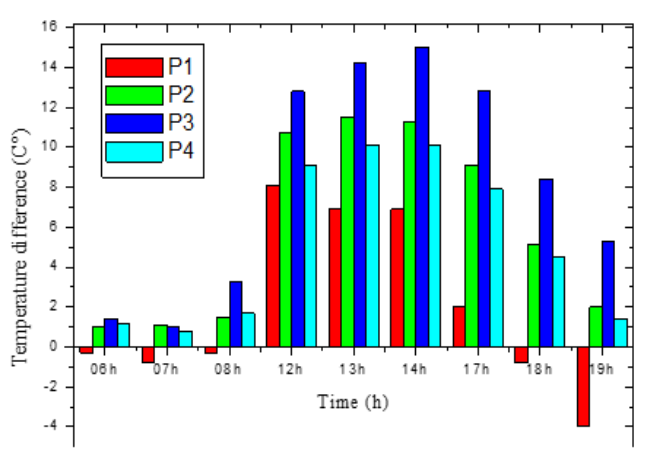

Figure 17. Internal and external temperatures variation during the day.

As problems that face us during the study, the longevity of the achievement in terms of building blocks and houses. Also the results are repeated several times to obtain satisfactory results, as it could not apply this study in a real house full of people.

\section{Conclusion:}

Through the experimental study, it is found that the building blocks completed from the burnt soil are suitable in our desert buildings, because their thermal resistance is good in addition to their availability in the market (Touggourt and Djemaa Factories). The fact that the polyester building blocks that have their thermal resistance is the largest among the tested building blocks as well as they have a very light weight, which only leads to thinking, even with the dimensions of the slab-bearing elements, and this has an effect on the economic side, except that their lack of presence in the market has a financial impact as well. As recommendations in this article, it's consider the following:

Building materials: Building materials that are as local as possible should be used. (Using stones and ensuring that they are linked to the following materials: Smelling, lime, clay, or using melded blocks made of clay supported with palm fibers). Resistant materials and few bad effects on the environment. As natural as possible and avoid synthetic materials. Heat and soundproof. If using clay, it should be applied in winter to avoid shrinkage. Through this study it's recommend the use of burnt or gypsum soil blocks because the raw material is available and the possibility of improving their properties through research is possible. Also, the architectural model must be adapted to the dry and hot climate, which allows the provision of a minimum of solar gain in summer and thermal loss in winter. For this reason, housing is directed towards the southeast to take advantage of sunlight in winter and protect from summer. 


\section{References}

[1] Peng $\mathrm{H}$, Li M, Lou S, He M, Huang $\mathrm{Y}$, Wen L. Investigation on spatial distribution and thermal properties of typical residential buildings in South China's Pearl River Delta. Energy and Buildings 2020;206:109555. https://doi.org/10.1016/j.enbuild.2019.109555.

[2] Oudrane A, Hamouda M, Aour B. The Thermal Transfers of a Habitable Envelope in an Extremely Dry Area and These Effects on Thermal Comfort. Algerian Journal of Renewable Energy and Sustainable Development, 2019, 1(1),79-91.

[3] Belatrache D, Bentouba S, Bourouis M. Numerical analysis of earth air heat exchangers at operating conditions in arid climates. International Journal of Hydrogen Energy 2017;42:8898-904. https://doi.org/10.1016/j.ijhydene.2016.08.221.

[4] Phap V, Nga N. Feasibility Study Of Rooftop Photovoltaic Power System For A Research Institute Towards Green Building In Vietnam. EAI Endorsed Transactions on Energy Web 2020;7.

[5] Kriker A, Debicki G, Bali A, Khenfer MM, Chabannet M. Mechanical properties of date palm fibres and concrete reinforced with date palm fibres in hot-dry climate. Cement and Concrete Composites 2005;27:554-64. https://doi.org/10.1016/j.cemconcomp.2004.09.015.

[6] Osman MM, Sevinc H. Adaptation of climate-responsive building design strategies and resilience to climate change in the hot/arid region of Khartoum, Sudan. Sustainable Cities and Society 2019;47:101429. https://doi.org/10.1016/j.scs.2019.101429.

[7] Numerical parametric study of a new earth-air heat exchanger configuration designed for hot and arid climates: International Journal of Green Energy: Vol 17, No 2 n.d. https://www.tandfonline.com/doi/abs/10.1080/15435075.2 019.1700121 (accessed July 20, 2020).

[8] Kapetanakis D-S, Mangina E, Finn D. Methodology for Commercial Buildings Thermal Loads Predictive Models Based on Simulation Performance. EAI Endorsed Transactions on Energy Web 2015;3.

[9] Chouaib A, Messaoud H, Salim M. Sizing, modelling and simulation for Hybrid Central $\mathrm{PV} /$ wind turbine/diesel generator for feeding rural village in South Algeria. EAI Endorsed Transactions on Energy Web and Information Technologies 2017;4.

[10] Belatrache D. Contribution to the optimization and improvement of the insulation of a dwelling using a renewable source in arid zones. phd. Adrar University, 2018.

[11] Scrivener KL, John VM, Gartner EM. Eco-efficient cements: Potential economically viable solutions for a low$\mathrm{CO} 2$ cement-based materials industry. Cement and Concrete Research 2018;114:2-26. https://doi.org/10.1016/j.cemconres.2018.03.015.

[12] Belferrag A, Kriker A, Khenfer ME. Improvement of the compressive strength of mortar in the arid climates by valorization of dune sand and pneumatic waste metal fibers. Construction and Building Materials 2013;40:84753. https://doi.org/10.1016/j.conbuildmat.2012.11.079.

[13] Al-Masawa MI, Manab NA, Omran A. The Effects of Climate Change Risks on the Mud Architecture in Wadi Hadhramaut, Yemen. In: Omran A, Schwarz-Herion O, editors. The Impact of Climate Change on Our Life: The
Questions of Sustainability, Singapore: Springer; 2018, p. 57-77. https://doi.org/10.1007/978-981-10-7748-7 3 .

[14] Zerboni A, Bernasconi A, Gatto MC, Ottomano C, Cremaschi M, Mori L. Building on an oasis in Garamantian times: Geoarchaeological investigation on mud architectural elements from the excavation of Fewet (Central Sahara, SW Libya). Journal of Arid Environments 2018;157:149-67.

https://doi.org/10.1016/j.jaridenv.2018.06.010.

[15] Lazarovich M, Casso E. Management and Restauration of Two National Historical Monuments of Earthen in Salta, Argentina. In: Aguilar R, Torrealva D, Moreira S, Pando MA, Ramos LF, editors. Structural Analysis of Historical Constructions, Cham: Springer International Publishing; 2019, p. 2089-96. https://doi.org/10.1007/978-3-31999441-3 224

[16] Belatrache D, Harrouz A, Abderrahmane A, Manaa S. Numerical Simulation of a Pseudo Plastic Fluid Through Sudden Enlargement. Algerian Journal of Renewable Energy and Sustainable Development, 2019, 1(1),92-98.

[17] Jasper A. Anthropology and Architecture: A Misplaced Conversation. Architectural Theory Review 2017; 21:1-3. https://doi.org/10.1080/13264826.2017.1289709

[18] Roesler S. The Urban Microclimate as Artefact: Reassessing Climate and Culture Studies in Architecture and Anthropology. Architectural Theory Review 2017;21:73-88.

https://doi.org/10.1080/13264826.2017.1288146.

[19] Changali S, Paul R. Role of Earthen Materials in Rural Vernacular Architecture: The Case of Anavangot Ancestral Home. In: Reddy BVV, Mani M, Walker P, editors. Earthen Dwellings and Structures: Current Status in their Adoption, Singapore: Springer; 2019, p. 437-46. https://doi.org/10.1007/978-981-13-5883-8_37.

[20] Rashid M, Ara D. Tectonics in the Gulf Architecture: 'Modernity of Tradition' in Buildings. In: Enteria N, Awbi $\mathrm{H}$, Santamouris M, editors. Building in Hot and Humid Regions: Historical Perspective and Technological Advances, Singapore: Springer; 2020, p. 137-50. https://doi.org/10.1007/978-981-13-7519-4_6.

[21] Hakkoum S, Kriker A, Mekhermeche A. Thermal characteristics of Model houses Manufactured by date palm fiber reinforced earth bricks in desert regions of Ouargla Algeria. Energy Procedia 2017;119:662-9. https://doi.org/10.1016/j.egypro.2017.07.093.

[22] Belferrag A, Kriker A, Abboudi S, Tié Bi S. Effect of granulometric correction of dune sand and pneumatic waste metal fibers on shrinkage of concrete in arid climates. Journal of Cleaner Production 2016;112:304856. https://doi.org/10.1016/j.jclepro.2015.11.007.

[23] Chaib H, Kriker A, Mekhermeche A. Thermal Study of Earth Bricks Reinforced by Date palm Fibers. Energy Procedia https://doi.org/10.1016/j.egypro.2015.07.827.

[24] CNERIB - Centre National d'Etudes et de Recherches Intégrées du Bâtiment n.d. http://www.cnerib.edu.dz/ (accessed July 20, 2020).

[25] Gorisse F. Essais et contrôle des bétons 1978

[26] Bendouba M, Djebli A, Baltach A, Benhamena A, Boukhlif A, Aid A. The Effect of the Size and Position of the Crack on the Normalized Stress Intensity Factor. Algerian Journal of Renewable Energy and Sustainable Development, 2020, 2(1),1-8.

[27] Oliva J-P, Courgey S. L'isolation thermique écologique: conception, matériaux, mise en øeuvre: neuf et réhabilitation. Terre vivante; 2011. 